\title{
ENSINO MÉDIO E EDUCAÇÃO PROFISSIONAL NO TEMPO PRESENTE: PARA ALÉM DA DUALIDADE ESCOLAR
}

\author{
Claudia Pereira de Pádua Sabia ${ }^{1}$, Silvio Cesar Nunes Militão² \\ ${ }^{1}$ Universidade do Oeste Paulista. e-mail: fsabia@uol.com.br. \\ ${ }^{2}$ UNESP/Presidente Prudente. e-mail: silvio@fct.unesp.br
}

\section{RESUMO}

A pesquisa foi realizada mediante procedimentos de levantamento e análises bibliográfica e documental, e teve como objetivo analisar as principais alterações sofridas pelo Ensino Médio e Educação Profissional decorrentes da aprovação do ordenamento legal vigente: Constituição Federal de 1988, Lei de Diretrizes e Bases da Educação Nacional - Lei nํ. 9.394/96 e Decreto n‥ 2.208/97, revogado pelo Decreto n․ 5.154/04. Parte de breve retrospectiva histórica acerca do surgimento e organização de tal escolaridade e, na sequência, examina as principais alterações sofridas pelo Ensino Médio e Educação Profissional trazidas pelo atual conjunto legal, consoante às orientações de reforma e racionalização do Estado, hegemônicas a partir dos anos 1990. Os resultados da pesquisa indicam que, até o momento, não foi possível ainda superar a dualidade histórica que tem prevalecido na etapa final da educação básica. Conclui, que o "Ensino Médio Inovador" pode ser um caminho viável para integração Ensino Médio e Educação Profissional.

Palavras-chave: Ensino Médio. Educação Profissional. Dualidade Escolar.

\section{HIGH SCHOOL AND VOCATIONAL EDUCATION IN THE PRESENT TENSE: BEYOND THE DUALITY SCHOOL}

\begin{abstract}
The survey was conducted by standard procedures for survey and analysis of literature and documents, and aimed to analyze the main changes experienced by high school and vocational education under the approval of the legal order in force: the 1988 Federal Constitution, Law of Directives and Bases of National Education - Law no. 9.394/96 and Decree no. 2.208/97, repealed by Decree no. 5.154/04. Part of a brief historical overview of the emergence and organization of schooling and such, following examines the main changes experienced by high school and vocational education brought about by the current set of laws, according to the guidelines of reform and rationalization of the state, from the hegemonic years 1990. The survey results indicate that, to date, we have not yet overcome the historical duality that has prevailed in the final stage of basic education. Concludes that the "Innovative School" may be a viable way to integrate high school and vocational education.
\end{abstract}

Keywords: High School. Vocational Education. Duality School. 


\section{INTRODUÇÃO}

No Brasil, o que hoje se denomina Ensino Médio, nasceu no período colonial, quando o modelo de produção era baseado na monocultura, no latifúndio e no trabalho escravo. Tal modelo excluiu, por séculos, a maioria da população brasileira da educação escolar, entendido mais como ilustração para poucos do que como um meio de formação e acesso ao conhecimento (PINTO, 2007).

Com consequências até os dias atuais, o modelo supracitado deu inicio a uma dualidade educacional no país: escola para ricos preparatória para os níveis escolares superiores e escola para pobres - destinada a qualificação profissional dos menos abastados para uma atividade profissional manual (TUPPY, 2007).

Historicamente marcados pelo caráter de classes, o Ensino Médio e a Educação Profissional, tornaram-se alvos recorrentes das reformas educacionais brasileiras gestadas e implementadas a partir da década de 1990, alinhadas às orientações neoliberais $e$ patrocinadas pelo Banco Mundial.

Nesse sentido, a presente pesquisa teve como objetivo analisar e discutir as principais alterações sofridas pelo Ensino Médio e Educação Profissional decorrentes da aprovação do ordenamento legal vigente, a saber: $\mathrm{CF} / 88$, LDB/96 e Decreto №. 2.208/97, revogado posteriormente pelo Decreto no. 5.154/04.

Para tanto, a pesquisa se valeu de levantamento e análises bibliográfica e documental sobre a temática em questão.

Assim, além de fazermos uma breve retrospectiva histórica acerca do surgimento e organização do Ensino Médio e da Educação Profissional no Brasil, apresentamos, na sequência, o atual conjunto legal que os normatiza/regula, desvelando suas implicações para manutenção e/ou superação do dualismo escolar que vem marcando tal escolaridade ao longo da história da educação brasileira.

\section{Ensino Médio e Educação Profissional: breve retrospectiva histórica}

Os padres jesuítas chegaram ao Brasil em 1549 e no final daquele ano fundaram, em São Vicente, um seminário-escola, que viria a ser o modelo de Ensino Médio no país por longo período. Seu currículo se estruturava por nove anos, envolvendo estudos como Retórica, Humanidades, Gramática Latina, Lógica, Metafísica e Moral, voltado à formação de sacerdotes, que se completava no nível superior. Contudo, as escolas secundárias jesuíticas também se apresentavam como única oportunidade dos filhos da elite local obterem a formação necessária para o ingresso nos cursos superiores da Europa (PINTO, 2007).

Após a expulsão dos jesuítas de Portugal em 1759, o orgânico (embora conservador e elitista) sistema jesuítico foi substituído pelas aulas régias, um sistema não seriado de aulas avulsas, com professores mal-remunerados e vitalícios no cargo, custeado por um novo tributo colonial instituído somente em 1772, o subsidio literário, que incidia sobre a venda de carne nos açougues e aguardente.

Os importantes acontecimentos da primeira metade do século XIX, como a vinda da família real portuguesa para o Brasil e a proclamação da sua independência, não alteraram o quadro deplorável da educação secundária do país.

Com o Ato Adicional de 1834, o poder central se reservou 0 direito de promover a educação superior no Império e a educação no Município da Corte, delegando às Províncias, a incumbência de promover a educação primária e a secundária. Essa descentralização trazida pelo Ato Adicional de 1834 acabou colocando a educação da elite, a cargo do poder central e a do 
povo, a cargo das Províncias que, "inteiramente entregues a si mesmas, desamparadas financeiramente pelo governo central, pouco puderam fazer em benefício da" educação primária e secundária. (HAIDAR; TANURI, 1998, p. 64).

No que se refere especificamente ao campo educacional, a instauração do regime republicano também não trouxe alterações significativas para a instrução pública brasileira, visto que a primeira Constituição da República pouco modificou a divisão de responsabilidades educacionais estabelecidas pelo Ato Adicional de 1834.

Embora existissem algumas experiências privadas, a formação profissional como responsabilidade do Estado, inicia-se no Brasil em 1909 com a criação de 19 escolas de artes e ofícios nas diferentes unidades da federação, precursoras das escolas técnicas federais e estaduais. Para Kuenzer (2001, p. 27),

[...] essas escolas, antes de
pretender atender as
demandas de r um
desenvolvimento industrial
praticamente inexistente,
obedeciam a uma finalidade
moral de repressão: educar,
pelo trabalho, os órfãos, pobres
e desvalidos da sorte,
retirando-os da rua.

Assim, na primeira vez que aparece a formação profissional como política pública, ela o faz na perspectiva moralizadora da formação do caráter pelo trabalho.

A Revolução de 1930 marca o inicio da era Vargas (1930-1945) e também de importantes transformações no campo educacional brasileiro. À frente do Ministério da Educação e Saúde Pública, o Ministro Francisco Campos baixou uma série de decretos dispondo sobre a organização do ensino superior, secundário e comercial.

\section{A chamada Reforma Francisco Campos} deu organicidade ao ensino secundário, estabelecendo definitivamente o currículo seriado, a frequência obrigatória e a exigência de habilitação para o ingresso no ensino superior. Com sete anos de duração, o curso secundário ficou dividido em 2 ciclos: fundamental (de cinco anos) e complementar (de 2 anos).

Para Romanelli (1992, p. 134) tal Reforma pecou por não estabelecer articulação entre os cursos secundário e profissional, com o último não dando acesso ao ensino superior. $\mathrm{A}$ reforma "tratou de organizar preferencialmente o sistema educacional das elites", deixando "completamente marginalizados os ensino primário e os vários ramos do ensino secundário profissional".

A reforma do ensino secundário iniciada por Francisco Campos foi complementada pelo Decreto-Lei o. 4.244/42, que se constituiu na Lei Orgânica do Ensino Secundário. Tal nível de ensino permaneceu com a mesma duração, mas foi subdivido nas seguintes etapas: ginásio (de quatro anos) e colegial (de três anos), modelo que foi mantido, em linhas gerais, até 1971.

Para Kuenzer (2001) a chamada Reforma Capanema instituiu, para as elites, os cursos médios de $2^{\circ}$ ciclo (cientifico e clássico), sempre destinados a preparar estudantes para o ensino superior. Para os trabalhadores, as alternativas de nível médio do $2^{\circ}$ ciclo eram o agrotécnico, o comercial técnico, o industrial e o normal.

Tal reforma organizou, também, os sistemas autônomos e isolados como o dos " $\mathrm{S}$ " (Senai, Sesi, Sesc, Senar e Sest) e o das escolas técnicas, voltados para a parcela mais carente da população. É desse período, também, a criação das escolas técnicas, a partir da transformação das escolas de artes e ofícios (1942).

[...] a dualidade estrutural, portanto, configura-se como grande categoria explicativa da constituição do Ensino Médio e profissional no Brasil, legitimando a existência de dois caminhos bem diferenciados a partir das funções essenciais do mundo da produção 
econômica: um, para os que serão preparados pela escola para exercer suas funções de dirigentes; outro, para os que, com poucos anos de escolaridade, serão preparados para o mundo do trabalho em cursos específicos de formação profissional, na rede pública ou privada (KUENZER, 2001, p. 28).

A Lei 5.692/71, segunda reforma da LDB/61, veio alterar sensivelmente a organização do ensino até então em vigor no país. Em primeiro lugar unificou o antigo ginásio com o antigo primário, criando o primeiro grau com oito anos de duração, obrigatório nas instituições públicas. Em segundo lugar, transformou o antigo colegial em segundo grau, sem alterar sua duração de três anos.

Contudo, a mais radical mudança implantada por esta lei foi à profissionalização compulsória do segundo grau. Assim, pela lei, todas as escolas de segundo grau deveriam assegurar uma qualificação profissional, fosse do nível técnico (quatro anos de duração) fosse de auxiliar técnico (três anos de duração).

Conforme Tuppy (2007), as tentativas de implantação da profissionalização compulsórias foram desastrosas em função de uma série de problemas e, assim, partiu como chegou, revogada pela Lei 7.044 .

\section{Ensino Médio e Educação Profissional no ordenamento legal vigente}

Do fim da profissionalização compulsória do Ensino Médio até a aprovação da LDB/96, tivemos uma ampliação do Ensino Médio sem a correspondente ampliação dos recursos necessários, bem como o progressivo abandono, por parte da classe média, da rede pública. Consolidaram-se as empresas de ensino na rede privada, em que o ensino é visto tão-somente como mercadoria a ser vendida para um mercado restrito, mas ávido pelo ingresso no ensino superior e disposto ao elevado sacrifício financeiro para tanto.

A primeira e mais importante modificação introduzida pela Constituição Federal de 1988, no que se refere ao Ensino Médio, diz respeito a sua abrangência. Conforme Pinto (2007, p. 52), no art. 208, inciso II,

[...] estabelecia que o dever do Estado com a educação escolar pública seria efetivado mediante a garantia de progressiva extensão da obrigatoriedade e gratuidade ao Ensino Médio. Este preceito aliado aos $\S \S 1^{\circ}$ e $2^{\circ}$ do mesmo artigo, que estabelecem que "o acesso ao ensino obrigatório é direito público subjetivo (o que significa que pode ser pleiteado no judiciário) e que o não oferecimento do ensino obrigatório, importa responsabilidade da autoridade competente e representavam instrumentos importantes para que $o$ estabelecido fosse de fato cumprido.

A Emenda Constitucional 14/96 alterou a redação do referido artigo, restringindo os direitos ali assegurados ao alterar para "progressiva universalização do Ensino Médio gratuito". Entretanto, na Lei de Diretrizes e Bases 9394, de 1996, aprovada após tal emenda, permaneceu a redação anterior da CF/88. Segundo Pinto (2007), o preceito que rege o Ensino Médio, quanto a sua abrangência é o da progressiva obrigatoriedade. Cabe destacar que, segundo alguns autores, esta mudança na redação do Ensino Médio perdeu a conceituação de direito público subjetivo, o que impede pleiteá-lo juridicamente e responsabilizar autoridades pela sua não oferta ou oferta irregular.

A responsabilidade pela oferta do Ensino Médio e da Educação Profissional no âmbito do poder público é basicamente dos sistemas estaduais, cabendo a União garantir um padrão mínimo de qualidade mediante assistência técnica e financeira. 
A LDB/96 prevê, basicamente, dois tipos de formação profissional: um que é incorporado na organização do ensino formal, particularmente no Ensino Médio, outro, também passível de certificação e reconhecimento, que é desenvolvido nos ambientes do trabalho, mas não exclusivamente nele.

Os $\S \S 2^{\circ}$ e $4^{\circ}$ do artigo 36 estabelecem que o Ensino Médio, atendida a formação geral do educando, poderá prepará-lo para o exercício de profissões técnicas e que "a preparação geral para o trabalho e, facultativamente, a habilitação profissional, poderão ser desenvolvidas nos próprios estabelecimentos do Ensino Médio ou em cooperação com instituições especializadas em Educação Profissional".

Há de se observar, ainda, que, embora a LDB/96 não tenha atribuído ao Ensino Médio o objetivo de profissionalização técnica, não tirou dele esta possibilidade. As escolas técnicas de nível médio, grande parte delas abarcadas pelos centros federais e estaduais de educação tecnológica, continuaram exercendo seu papel, no tocante as formações geral e técnica, que somente teve mudança significativa a partir do Decreto n․ 2.208/97.

Os chamados cursos de segundo grau profissionalizantes ou técnicos ofereciam, na mesma escola e com algum nível de integração, a formação geral, (sob denominação de núcleo comum do currículo) e a formação técnica (sob denominação de disciplinas específicas). Embora, de fato, esta integração sempre tenha sido muito tênue, como já analisado, sob o foco de direito, ela estava preservada, o que concedia ao menos a possibilidade de sua realização.

Mas o Decreto 2.208/97 alterou profundamente esta condição, na medida em que propôs separá-las de fato e de direito. Basicamente, o Decreto №. 2.208/97 teve como objetivo expandir as matrículas no ensino técnico (com foco na formação de mão-de-obra para o mercado de trabalho) e diminuir o custo unitário deste tipo de formação.

Para Tuppy (2007, p. 114), este decreto representaria o reforço da dualidade escolar, "contribuindo para a estamentização das situações de classe". Segundo a autora, neste sentido, a regulamentação dada pelo Decreto 2.208/97 e pelas Diretrizes Curriculares Nacionais para o Ensino Médio e Técnico foi contestada por não atingir os objetivos de democratização e de melhoria da qualidade da Educação Profissional e por não atender à crescente demanda de formação integral, pleiteada pelos movimentos progressistas, e capazes de oferecerem subsídios para a emancipação da classe trabalhadora utopia indispensável à transformação da realidade.

Em julho de 2004, atendendo em parte as pressões e buscando cumprir os compromissos de campanha, o Governo Lula revogou o Decreto №. 2.208/97 por meio do Decreto №. 5.154/04 que passou a regulamentar o $\$ 2^{\circ}$ do art.36 e os artigos 39 a 41 da LDB/96.

Na precisa avaliação de Bueno,

[...] os itinerários formativos por área, instituídos pelo decreto $5.154 / 04$, que reformula as diretrizes políticas para a Educação Profissional, são frágeis e sua regulamentação pouco experimentada, o que torna a redefinição curricular um assunto em processo de debate. No discurso governamental, o supracitado decreto é visto apenas como medida de transição, forçosamente necessária por conta dos problemas gerados pelo decreto no. 2.208/97, que regulamentava 0 assunto $e$ seus desdobramentos (BUENO, 2005, p. 139).

Com a revogação do decreto 2.208/97 restabeleceu a possibilidade de integração curricular dos ensinos médio e técnico; há, de fato, um longo caminho a ser percorrido para 
superar a fragmentação da formação profissional de nível médio, considerando-se particularmente a ausência de uma política pública que dê conta de integrar programas isolados e contingentes que têm caracterizado as iniciativas de formação profissional, em detrimento de um projeto mais amplo.

\section{CONCLUSÃO}

Após 14 anos da LDB, os dados e as avaliações oficiais revelam que ainda não foi possível superar a dualidade histórica que tem prevalecido no Ensino Médio, tampouco garantir a universalização, a permanência e a aprendizagem significativa para a maioria de seus estudantes.

O Ensino Médio vem sendo penalizado com a escassez de recursos desde a lei da profissionalização compulsória, em que muitas escolas foram sucateadas. O FUNDEF, ao priorizar o ensino fundamental, deixou poucos recursos para 0 Estado investir em tal escolaridade. Sem dúvida, o FUNDEB - em vigor desde 2007 - representou significativo avanço para oferta de toda a educação básica. Contudo, é forçoso reconhecer seus limites para a garantia de um Ensino Médio e Educação Profissional em quantidade e qualidade.

Em junho de 2009 foi divulgado o documento chamado "Ensino Médio Inovador", contendo o novo currículo que pretende integrar Ensino Médio e a Educação Profissional com uma carga horária de 3.000 horas/aula. A intenção é promover a interdisciplinaridade e deixar 0 currículo mais flexível, com $20 \%$ da grade curricular a ser escolhida pelo aluno. Segundo esta proposta, a identidade do Ensino Médio se define na superação do dualismo entre propedêutico e profissionalizante.

$\mathrm{O}$ atual governo, com o "Ensino Médio Inovador", busca tornar a etapa final da educação básica mais atrativa para os jovens, contemplando tanto a formação geral quanto a qualificação para o trabalho, tendo em vista superar a histórica dualidade escolar que marca tal escolaridade. Para tanto, necessitará de investimentos suplementares aos disponibilizados atualmente pelo FUNDEB uma vez que é preciso reformar escolas, comprar equipamentos e materiais, qualificar os professores e garantir-lhes remuneração adequada.

É notório que a tarefa que ainda está para se fazer é grande, necessitando de vontade política e empenho para sua materialização. Em contrário, corre-se o risco de uma "reedição" das consequências da Lei 5692/71.

\section{REFERÊNCIAS}

BUENO, M. S. S. Formação Docente para a Educação Técnica e Profissional de Nível Médio. In: PARDAL, L.; VENTURA, A.; DIAS, C. (orgs.). Ensino Médio e Ensino Técnico no Brasil e em Portugal: raízes históricas e panorama atual. Campinas: Autores associados, 2005.

HAIDAR, M. de L. M.; TANURI, L. M. A educação básica no Brasil: dos primórdios até a primeira Lei de diretrizes e Bases. In: MENESES, J. G. et al. Estrutura e funcionamento da educação básica: leituras São Paulo: Pioneira, 1998.

KUENZER, A. Z. Ensino Médio: construindo uma proposta para os que vivem do trabalho. São Paulo: Cortez, 2001.

PINTO, J. M. R. O Ensino Médio. In: OLIVEIRA, R. P.; ADRIÃO, T. (orgs.). Organização do Ensino no Brasil: níveis e modalidades na Constituição Federal e na LDB. São Paulo: Xamã, 2007.

ROMANELLI, O. História da educação no Brasil: 1930-1973. Petrópolis: Vozes, 1992.

TUPPY, M. I. N. A Educação Profissional. In: OLIVEIRA, R. P.; ADRIÃO, T. (orgs.). Organização do Ensino no Brasil: níveis e modalidades na Constituição Federal e na LDB. São Paulo: Xamã, 2007. 